\title{
Spät zu Bett gehende Kleinkinder werden dicker
}

\author{
Eine Langzeitbeobachtung zeigt, dass Vorschulkinder, die spät ins Bett \\ gehen, im Jugendalter ein deutlich erhöhtes Adipositasrisiko haben.
}

_ Die prospektive US-amerikanische Study of Early Child Care and Youth Development untersucht den Einfluss verschiedener mütterlicher Faktoren auf die kindliche Entwicklung. Dabei geht es auch um den Einfluss des frühen Zubettgehens im Vorschulalter sowie von Bindungskomponenten zwischen Mutter und Kind auf das Adipositasrisiko.

Die Probanden wurden 1991 als Babys an 24 Krankenhäusern in neun Bundesstaaten rekrutiert. 1995-1996 wurde per Fragebogen die Zubettgehzeit ermittelt. Im Alter zwischen 12 und 15,9 Jahren wurde der Body-Mass-Index (BMI) erhoben. Die Daten von 1.364 Teenagern lagen vor, 977 wurden in die Studie eingeschlossen.

Für die Analyse wurden drei Gruppen betrachtet. Etwa ein Viertel ging regelmäßig vor 20 Uhr ins Bett, die Hälfte zwischen 20 und 21 Uhr und ein weiteres Viertel nach 21 Uhr. Das Verhalten der Mütter ihren Kindern gegenüber wurde nach vorheriger Einweisung in bestimmten Spielsituationen durch Analyse eines 20-minütigen Videoclips von Experten bewertet. Dabei ging es um die Bindungsfähigkeit der Mütter, die auch als „Feinfühligkeit“ (,sensitivity“) bezeichnet wird.

Von den früh schlafenden Kindern hatten $10 \%$ im Jugendalter eine Adipo- sitas nach internationalen Kriterien. In der mittleren Gruppe waren es $16 \%$, und von den spät zu Bett gehenden Probanden 23\%. Signifikanten Einfluss hatten männliches Geschlecht, Zugehörigkeit zur schwarzen Rasse, hohes Geburtsgewicht, Ausbildung der Mutter, niedriges Familieneinkommen und Adipositas der Mutter - aber nicht die Feinfühligkeit der Mutter. Nach Ausschluss aller Störfaktoren blieb die Beziehung zwischen Zubettgehzeit und Adipositas statistisch signifikant. Wer im Vorschulalter früh schlafen ging, hatte ein halb so hohes Risiko für eine Adipositas im Jugendalter wie Kinder, die spät zu Bett gingen.

- Andersen SE, Andridge R, Whitaker RC. Bedtime in preschool-aged children and risk for adolescent obesity. J Pediatr 2016;176:17-22

\section{KOMMENTAR}

Einige frühere Studien hatten diese Abhängigkeit bereits gezeigt. Neu ist nun der lange Beobachtungszeitraum - und der Nachweis, dass die Bindungsfähigkeit der Mutter in diesem Kontext keinen Einfluss hat. Die Autoren schränken ein, dass es sich um eine Beobachtungsstudie handelt, die Zubettgehzeiten telefonisch erfragt wurden, Schlafdauer und Schlafqualität unbekannt blieben und die Wochenenden nicht abgedeckt wurden. Es ist denkbar, dass die Eltern und damit auch die Kinder in der Gruppe mit früher

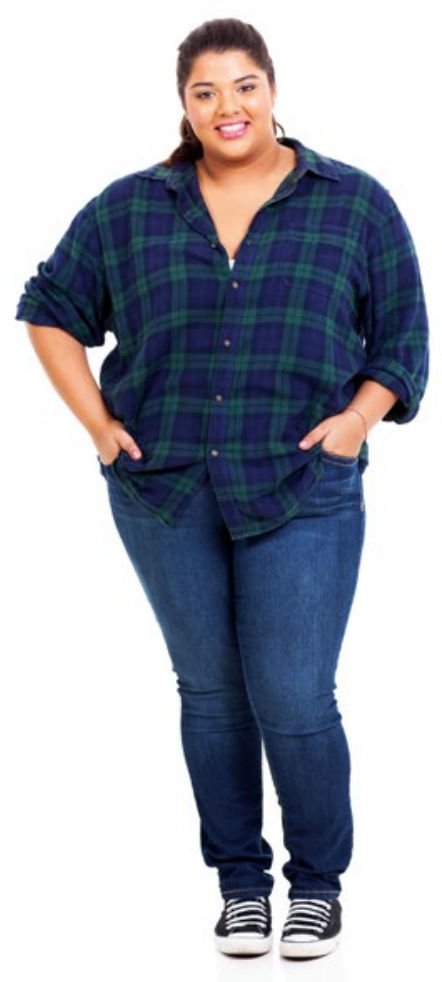

Schlafzeit allgemein disziplinierter waren. Diese Disziplin könnte auch das Essverhalten des Nachwuchses bestimmen. Die Studie berücksichtigte allerdings soziökonomische Faktoren. Es kann daher nur spekuliert werden, dass ein spätes Zubettgehen mit einem konsekutiv höheren Konsum von Süßigkeiten, Nüssen, Popcorn und Ähnlichem z. B. während des Fernsehens verbunden sein könnte. Zirkadiane Schwankungen von Hormonen, die den Fettstoffwechsel beeinflussen, könnten eine Rolle spielen.

Prof. em. Dr. med. Dr. h.c. D. Reinhardt

\section{Hier steht eine Anzeige.}

